\title{
How interpreters influence patient participation in medical consultations: The confluence of verbal and nonverbal dimensions of interpreter-mediated clinical communication
}

\author{
Demi Krystallidou ${ }^{\mathrm{a}, *}$, Peter Pype ${ }^{\mathrm{b}}$ \\ ${ }^{\mathrm{a}} \mathrm{KU}$ Leuven, Faculty of Arts (Antwerp campus), Antwerp, Belgium \\ ${ }^{\mathrm{b}}$ Ghent University, Department of Family Medicine and Primary Health Care, Ghent, Belgium
}

\section{A R T I C L E I N F O}

\section{Article history:}

Received 21 August 2017

Received in revised form 27 April 2018

Accepted 4 May 2018

\section{Keywords:}

Patient participation

Patient involvement

Communication barriers

Nonverbal communication

Video recording

A.R.T. Framework

Interpreter-mediated consultations

\begin{abstract}
A B S T R A C T
Objective: To investigate i) how the patient's participation in interaction occurs in interpreter-mediated consultations (IMCs) when the doctor provides information to the patient or tries to elicit information from them; ii) how the interpreter's presence in the consultation influences the patient's participation. Method: We analyzed 20 authentic video-recorded IMCs using the A.R.T. framework, an analytical tool for the study of participation in video recorded interpreter-mediated interactions.

Results: We coded 521 doctor utterances through which doctors either provided information or tried to elicit information from the patient. In 448 of them, the interpreter established a participation and engagement framework (PEF) with the patient while translating the doctor's utterances. In 48 cases the interpreter established a PEF with the doctor and in 25 cases the interpreter avoided establishing a PEF with either of the participants while translating the doctor's utterances.

Conclusion: When the interpreter established a PEF with either of the participants, they used verbal and nonverbal means that created the conditions in interaction in order to enable and/or rectify the patient's participation.

Practice implications: Doctors and interpreters should become more aware of their own and each other's actions in interaction and their influence on the patient's participation in the consultation.
\end{abstract}

(c) 2018 Elsevier B.V. All rights reserved.

\section{Introduction}

Patient participation is an essential aspect of patientcentered care [1]. Studies have associated patients' level of active participation with a variety of outcomes, such as improved psychological well-being [2] and treatment adherence [3]. Yet, a growing body of research on communication in which the patient's companion (e.g. spouse) participates in the consultation has shown that patients participated less than they did in consultations where only they and the doctor were present [4]. In the presence of a companion, it is more likely for the patient to be presented with limited opportunities for participation in the communication with the doctor, as the companion might be acting in ways that decrease the interaction time between the patient and the doctor [5,6]. More

\footnotetext{
* Corresponding author at: KU Leuven, Faculty of Arts (Antwerp campus), Sint-Andriesstraat 2, B-2000 Antwerp, Belgium

E-mail address: demi.krystallidou@kuleuven.be (D. Krystallidou).
}

specifically, they might respond on the patient's behalf [7] and their mere presence in the consultation room might inhibit patient's disclosure [8].

The above findings have emerged from the analysis of monolingual consultations. However, there is a constantly expanding linguistic and cultural diversity in the patient population and an increase in the number of language discordant consultations which deserves attention. Such consultations are often enabled by interpreters. When it comes to the interpreter's position in interaction it is widely acknowledged in the Interpreting Studies literature that interpreters are fully fledged participants in interaction while striving to maintain their own impartiality. Although they do not take sides, they participate in interaction in similar ways doctors and patients do (e.g. using similar verbal and nonverbal means). However, in practice there is still a misconception of the interpreter's position with doctors perceiving interpreters either as "black boxes" and "translation machines" providing almost literal translations, or even as culture experts and mediators [9-11]. This misconception shapes participants' expectations of the interpreter. For instance, when 
interpreters are perceived as "black boxes" and "translation machines", they are expected to only translate from one language to another without changing the dynamics of the interaction. However, research in interpreter-mediated interaction has provided evidence of the interactional dynamics being shaped by the interpreter's presence (e.g. turn-taking, gaze behaviour and body orientation differ between monolingual and interpreter-mediated interactions). Research has also shown that interpreters' actions (verbal and nonverbal), like the primary participants' actions, shape interaction and are shaped by it [12,13].

Considering that utterances in interpreter-mediated consultations (IMCs) are rendered twice (first in the original- then into the second language) which has an impact on the speaking time, and also that interpreters might edit, or even omit, parts of the utterances they translate $[14,15]$, it could be assumed that patient participation in IMCs might be compromised, too. However, further evidence is required to ascertain this. It could be argued that patients not speaking the doctor's language are unable to participate in the consultation. In this paper we rely on the assumption that professional interpreters provide patients access to the doctors' utterances and in so doing they enable patients to participate in the interaction with the doctor and the other way around. In this way patients in IMCs can participate in similar ways doctors and interpreters do.

Given the increasing demand for IMCs and the dearth of empirical investigation of patient participation in IMCs, there is a need for exploratory research with a focus on the interactional processes in patient participation in IMCs. We want to contribute to this strand of research by taking a more comprehensive perspective on interaction and studying not only participants' verbal but also nonverbal behaviour. We will do so by investigating the following research questions:

\section{- How does the patient's participation in interaction occur in IMCs when the doctor provides information to the patient or tries to elicit information from them? \\ - How does the interpreter's presence in the consultation influence the patient's participation in interaction?}

\section{Method}

\subsection{Data}

We report on data taken from a corpus of 20 video-recorded authentic IMCs collected in an urban hospital in Flanders, Belgium. The consultations were conducted in Dutch (the doctors' native language), Russian, Turkish and Arabic (the patients' native languages) and were held by 20 doctors ( 15 male, 5 female, $37-58$ years old) and 20 patients ( 13 female, 7 male, $18-75$ years old)and were enabled by 8 interpreters (6 female, 2 male, 35-50 years old). The patients did not have a command of Dutch. The topic of the consultations ranged from cardiovascular diseases, endocrine disorders, and hematological malignancies to HIV. The length of the consultation ranged approximately from 20 to $90 \mathrm{~min}$. The interpreters were trained and certified. All research participants were blinded to the research questions. None of the researchers was in the consultation room. For the video-recording a high definition SONY video-camera was used. The camera was placed behind the interpreter and the patient ensuring their gaze could be visible. The study was approved by the hospital ethics committee (Belgian registration number: B67020095716). Participants' written informed consent was obtained. The corpus was transcribed and translated into Dutch by professional translators and checked for accuracy by native speakers with a background in (applied) linguistics.

\subsection{Coding}

Two coders (DK, PP) coded independently the doctors' utterances for "information provision" or "information elicitation" by watching the video recordings and consulting the transcript of the consultation. "Information provision" comprised a doctor's utterance within which the doctor provided information to the patient (e.g. communicating diagnosis, explaining treatment plan). In utterances coded as "information elicitation" the doctor invited the patient to disclose information about their medical condition or psycho-social background (e.g. by asking open-ended questions). Of all coded utterances $(n=521) 442$ were identical between the two coders and consensus was reached through discussion on the remaining 79 coded utterances.

\subsection{Analytical tool}

We performed a multimodal interaction analysis to the coded utterances by drawing on the A.R.T. framework. In every previously identified utterance we coded the doctor's, patient's and interpreter's gaze, body orientation and interactive hand gestures, as shown in Bavelas et al. [16], in relation to each participant (e.g. doctor looking at the interpreter, pointing at the patient while having his body oriented to the interpreter). We focused on interactive hand gestures as those are used by speakers to include the addressee of their utterance [16]. Consensus was reached between the authors on the coding of utterances, gaze, body orientation and hand gestures. A number of recurrent patterns in the participants' gaze, body orientation and use of gestures were registered. In this paper we discuss only the most prominent patterns of the coded instances of interaction.

The A.R.T. framework [13] is an analytical tool for the study of participation in interpreter-mediated interactions (Table 1). The tool focuses on action and language rather than language alone, allowing for closer analysis of the various complex interactional phenomena (e.g. combination of verbal and nonverbal interaction) that occur at more or less the same time in IMCs.

We started our analysis by defining the Actions performed by the doctor and the way they relate to the patient and interpreter. In the A.R.T. framework Actions refer to participants' verbal utterances which at the following stage of the analysis (Ratification) are complemented by the study of participants' gaze, body orientation and interactive hand gestures.

We opted to focus on the doctor's provision of information to the patient and on their elicitation of information from them, as these serve as a basis for patient participation. We focus on the doctor because it is the doctor who informs the patient and invites them to participate in the consultation (14).

Participants in interaction might at times communicate exclusively by nonverbal means, such as gaze and gestures, when, for instance, they want to give the floor or when they signal that they are listening [17]. In IMCs the doctor might be speaking to the interpreter while communicating nonverbally with the patient [10].

The next stage of analysis (Ratification) focused on the ways in which the doctor, patient and interpreter relate to each other in interaction by identifying speaker and hearer roles (Table 1 ). This allowed us to distinguish the different degrees of responsibility the doctor, patient and interpreter hold for the meanings expressed. This sheds further light on the way in which they relate to each other during the consultation.

In order to look into the ways in which doctors, patients and interpreters ratify (and are ratified by) each other, we relied on the concept of "participation and engagement frameworks" (PEFs) [18,19]. PEFs are useful devices that 
Table 1

The A.R.T. framework.

\begin{tabular}{|c|c|c|}
\hline Step 1: & $\begin{array}{l}\text { A } \\
\text { (action): }\end{array}$ & Identifying what participants do within a specific situation by asking "who is doing what?" \\
\hline Step 2: & $\begin{array}{l}\mathrm{R} \\
\text { (ratification): }\end{array}$ & $\begin{array}{l}\text { Identifying the ways in which participants behave to each other in interaction. This can be done by identifying speaker and } \\
\text { hearer roles and, at the same time, observing the ways in which participants signal to each other when their own turn is finished } \\
\text { and when another participant may take the floor. } \\
\text { Speakers assume the following roles: author (the originator of an utterance, both in terms of content and in terms of the words } \\
\text { used), principal (the one who is responsible for what is being said), and animator (the one who simply repeats someone else's } \\
\text { words). } \\
\text { Hearers can be addressed (ratified) and/or unaddressed (unratified). } \\
\text { Ratification occurs verbally and non-verbally (e.g. by means of gaze, body orientation, gestures) and can be observed by relying } \\
\text { on the concept of "participation and engagement frameworks" (PEFs). PEFs are created by participants' body orientation } \\
\text { (displaying (un)availability for participation in a participation framework) and gaze (displaying (dis) engagement vis-à-vis a } \\
\text { participant's talk). }\end{array}$ \\
\hline Step 3: & $\begin{array}{l}\mathrm{T} \\
\text { (task): }\end{array}$ & $\begin{array}{l}\text { Identifying actions participants should perform and behaviour they should display according to the normative frameworks to which } \\
\text { they are subject. Norms are disseminated though codes of conduct / ethics, educational programmes, as well as guidelines on effective } \\
\text { clinical communication. }\end{array}$ \\
\hline
\end{tabular}

allowed us to illustrate nonverbal dimensions alongside verbal interaction in which interactants participate in a communicative event (e.g. medical consultation). Therefore, we conceptualize inclusion in a participation,- engagement framework or PEF as one of the ways participants include themselves and others into participation. For instance, the more patients are included in a PEF with their doctor, the higher their level of participation is.

In PEFs interactants display availability for interaction with each other by shifting their body orientation to include themselves and others in the participation framework. In a similar vein, they shift their gaze to the interactant whose talk they want to engage in. Aversion of gaze displays lack of interest or disapproval [20]. Each time a participant shifted their gaze to another participant who responded by means of gaze, this was coded as an engagement framework. Each time a participant shifted their body orientation to another participant who responded by means of body orientation, this was coded as a participation framework. If both gaze and body orientation were shifted to a participant who responded by means of both, then this was coded as a PEF. The influence of engagement (through gaze) and participation (through body orientation) was at times mediated by participants' interactive hand gestures.
The third level of analysis (Task) refers to the doctors' and interpreters' normative role (e.g. codes of professional practice).

While the Actions and Ratification aspects of the analytical framework focus on the observation of the interactants' behaviour, the Task part allows for a reflection on the observed behaviour through the lens of normative frameworks that interactants in the medical consultation are subject to. For this reason, we incorporate the Task aspect into the Discussion section.

\section{Results}

We identified four ways in which the patient's participation occurs in IMCs when the doctor provides information to the patient or tries to elicit information from them. We coded 521 doctor utterances toward patients in which the interpreter performed actions that went beyond the provision of an almost literal translation. In 448 of them (86\%), the interpreter established a PEF with the patient while rendering the doctors' utterances (way 1 ). In 73 cases, the interpreter did not form a PEF with the patient while translating the doctor's utterance, but they either established a PEF with the doctor (e.g. by seeking clarification on the doctor's utterance before translating it) (way 2; 48 cases; 9\%) or they avoided establishing a PEF with either of the participants (e.g. the interpreter adopted a neutral posture and kept looking at their notes) (way 3; 25

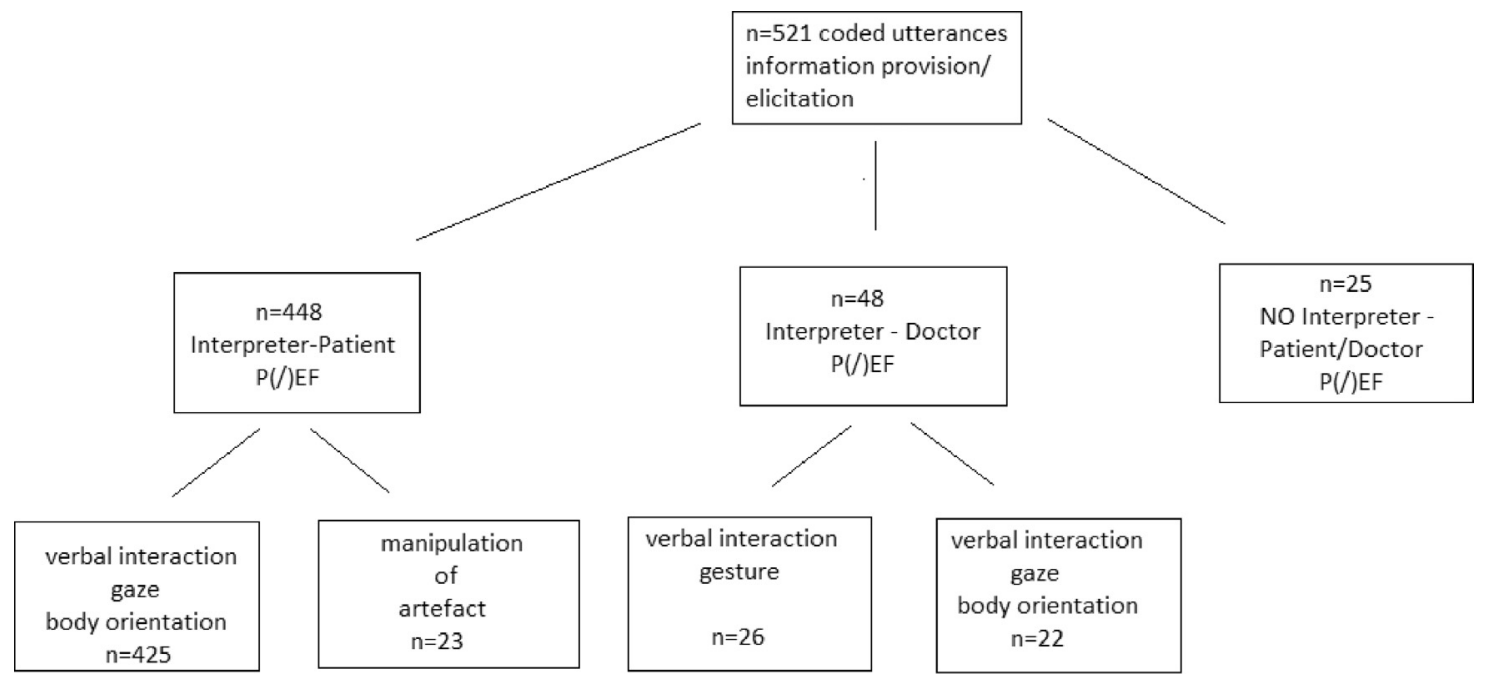

Fig. 1. Coded utterances and patterns of non-verbal behaviour. 
cases; $5 \%$ ). When the interpreter did not establish a PEF with either of the participants, they assumed the role of animator and provided almost a literal translation. In that case the patient's participation in interaction was subject to the doctor's utterances and style of communication (way 4). We discuss only the first three ways, as our interest lies primarily in the interpreter's influence on the patient's participation in interaction.

Below, we illustrate the three most prominent ways in which the interpreter created most often conditions in interaction in order to enable and/or rectify the patient's participation: i) the interpreter included the patient in interaction by means of verbal interaction, gaze and body orientation (when establishing a PEF with the patient) $(\mathrm{n}=425)$, ii) the interpreter included the patient in interaction by means of manipulation of an artifact (when establishing a PEF with the patient) $(n=23)$, iii) the interpreter included the patient in interaction by means of verbal interaction and gesture (when establishing a PEF with the doctor) $(n=26)$ (See Fig. 1 ). The coded gestures were turn gestures [16] the interpreter used either to claim a turn from the doctor or give turn to the patient.

\section{Interpreter-patient PEF}

4.1. The interpreter includes the patient in interaction by means of verbal interaction, gaze and body orientation

Boxes 1 and 2 provide an illustration of the interpreter's attempt to include the patient in interaction by means of verbal interaction, gaze and body orientation.

Box 1. (D: doctor, P: patient, I: interpreter; (.): pause shorter than 2secs; //: overlapping talk).

49 D: $\quad$ ja (.) dus (.) e:eh wij weten in de bloedstolling zijn heel veel factoren e:ehm die daarvoor moeten zorgen dat het bloed kan klonteren en daarvan zijn er een aantal bij haar onderzocht om te kijken e:eh wat dat er mis is met de bloedstolling hé? want zo klonters maken op een jonge leeftijd is meestal niet normaal en daarbij is er e:en eerste test gevonden een afwijking in factor 5 en die hebben allemaal een nummer (.) een afwijking in factor 5 die daarvoor zorgt dat eigenlijk dat de stolling te lang actief blijft (.) en dat dan klonters kan geven

\begin{abstract}
yes (.) so (.) e:eh we know that in the coagulation there are a lot of factors eh: ehm which enable the blood to clot and some of which have been analysed in her blood test in order for us to find out what is wrong with the coagulation hey? because such clots at such an early age are mostly abnormal and in an initial test a deviation in factor 5 was found and all of them have a number (.) a deviation in factor 5 which results in the coagulation being active $f$ for too long (.) and that this can give clots)
\end{abstract} слишком быстро сворачивается если слишком много вот этих тромбочек появляется (.) А и очень странно что вы в молодом возрасте у вас уже появляются вот такие тромбочки поэтому они (.) провели некоторые тесты (.) и (.) на различные факторы все факторы имеют свои номера (.) Провели фактор (.) тест на отклонение фактор и - пятом (.) Фактор и 5-ом обозначает что// so they have there are different factors which make blood coagulate too fast if there are many of these factors then clots appear (.) it is really strange that at such an early age you already have such clots (.) therefore they have done some tests on different factors (.) each factor has a number (.) factor 5 was checked (.) factor 5 means that//) 
Box 2. (D: doctor; I: interpreter; P: patient; 4: direction of gaze; (.): pause shorter than 2 secs; : : sound elongation; //: overlapping talk).
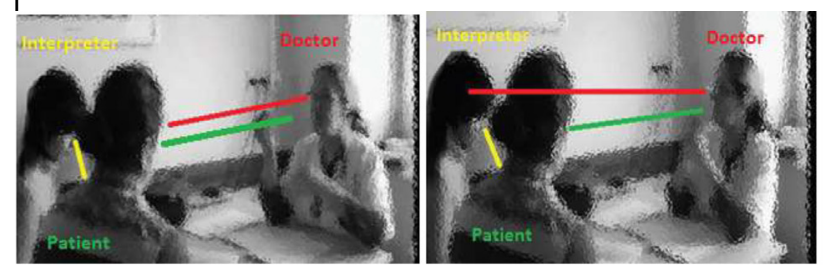

49a D 4P:yes (.) so (.) e:eh

$49 \mathrm{~b} \mathrm{D}<\mathrm{I}$ we know that in the coagulation there are a

lot of factors eh: ehm which enable the

blood to clot and some of which have been

analysed in her blood test in order for us to

find out what is wrong with the coagulation

hey? because such clots at such an early age

are mostly abnormal
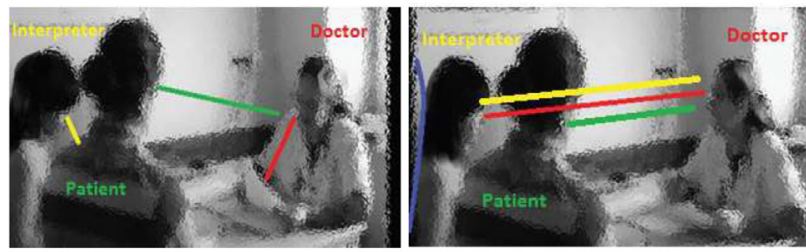

$49 \mathrm{C} \backsim$ documents and in an initial test

49d D 4 I in factor 5 was found and all of them

deviation

have a number (.) a deviation in
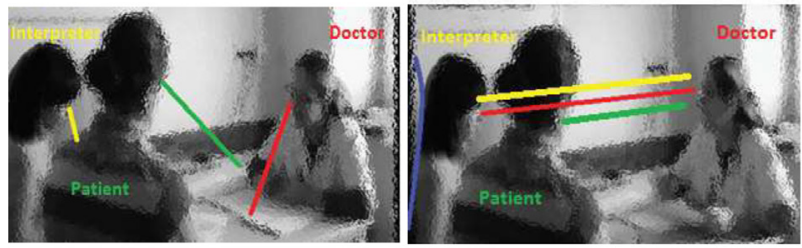

49e $D$ documents factor 5 which results in the

49 f $D \&$ for too long (.) and that this can give clots

coagulation being active

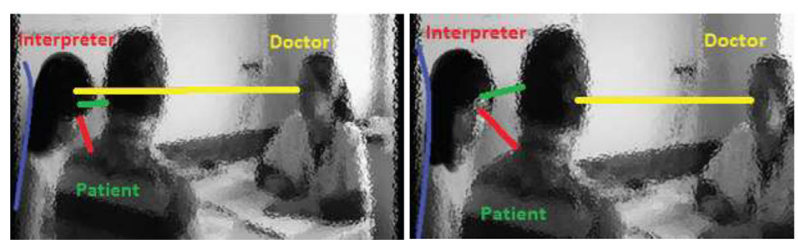

$5014 \mathrm{P} /$ notes so they have there are different factors which make blood coagulate too fast if there are many of these factors then clots appear (.) it is really strange that at such an early age you already have such clots (.) therefore they have done some tests on different factors (.) each factor has a number (.) factor 5 was checked (.) factor 5 means that//

In response to the question "who is doing what", we identified the following Actions: i) The doctor is providing information on coagulation and explains the result of the patient's blood test; ii) the interpreter is translating the doctor's utterance for the patient.

For the identification of Ratification patterns, we consulted the video extract (Box 2).
The doctor's brief ratification of the patient (49a) is followed by the doctor's ratification of the interpreter, leading gradually to a PEF with her (49d and 49f) from which the patient is excluded. The patient's gaze and body orientation remain again remarkably the same, projecting availability for interaction with the doctor and engagement in her turns, despite the language barrier. Soon, the interpreter assumes the role of author (the interpreter edits the doctor's preceding utterance), ratifies the patient verbally and tries to initiate a PEF with her to which the patient responds later on through gaze (engagement framework) (50). The interpreter's body orientation changes slightly, as she leans toward the patient's side, while her gaze is divided between the patient and her note-pad. The patient's body orientation remains the same as before, displaying availability for interaction with the doctor, despite the patient's inclusion in the engagement framework with the interpreter. The doctor's gaze is divided between the interpreter and the patient, projecting engagement in the interpreter's talk and the way in which it is received by the patient.

4.2. The interpreter includes the patient in interaction by means of manipulation of an artifact

In addition to gaze, body orientation and verbal interaction, the interpreters in our dataset involved the patient by manipulating an artifact. Box 3 and Box 4 illustrate such a case in which the interpreter checks the patient's pills and ultimately uses a packet of his pills as a means of rectifying the patient's participation in interaction with the doctor.

In turn 78 , the doctor verbally ratifies the interpreter, whom she informs of the patient's prescribed medication. In the doctor's utterance, an underlying attempt to secure understanding with the interpreter can be noticed. The doctor's intonation in the video reveals that she seems surprised when she finds out that the patient has again been prescribed medication he has already been taking. The interpreter in turn 79 recognizes the doctor's surprise and implicit request to secure understanding and therefore takes the liberty of asking the patient two questions which were not introduced by the doctor (are you still taking them? Do you take Nestolan during the night?). In so doing, the interpreter steps out of the role of animator and acts as an author and principal (i.e. she edits the doctor's preceding utterance and introduces new pieces of information).

It could be argued that there is a participation framework between the interpreter and the patient (81), as their bodies are oriented towards each other. The doctor seems to be excluded from the interpreter-patient participation framework, as she does not establish mutual gaze with either of them and she keeps working on her computer. However, the interpreter, while still leaning toward the patient, accepts the doctor's verbal ratification (80), assesses the validity of the doctor's utterance and takes the initiative to repair the doctor's understanding of the patient's seemingly positive reaction (81) which is a response to the interpreter's question to the patient (79). The interpreter clarifies the patient's participation by manipulating an artifact, the patient's pills, which she uses as a means of adjusting the patient's participation in the interaction with the doctor.

\section{Interpreter-Doctor PEF}

5.1. The interpreter includes the patient in interaction by means of verbal interaction and gesture

Boxes 5 and 6 illustrate the end of a series of doctor's utterances in which he provides information on the patient's incomplete 
insurance, inviting the patient to share more information on the status of her insurance. The patient requested to be excluded from the picture. Boxes 5 and 6 start with the patient's response to the doctor. The interpreter includes the patient by creating space for her voice to be heard, despite the doctor's attempt to finish the consultation. The interpreter does so by blocking the PEF that was initiated by the doctor by shifting his gaze and orientating his body to the interpreter (106a) in his attempt to catch the interpreter's attention. The interpreter responds to the doctor's PEF only at a later stage and after the doctor has moved his gaze and oriented his body to the patient. As soon as the doctor again verbally ratifies the interpreter by announcing to her that he wants to end the consultation, the interpreter steps out of the typical animator role, assumes for a while the role of author and principal (the lady says), adopts posture and gaze showing unavailability for interaction with the doctor and raises her index finger to him in order to demand space for the patient's voice to be heard. The doctor accepts the interpreter's verbal ratification and grants permission to the interpreter to proceed with the translation of the patient's utterance (108).

Box 3. (D: doctor, P: patient, I: interpreter; (.): pause shorter than 2secs; //: overlapping talk).

78 D: Ik ga een keer juist zijn medicatie ook nakijken (.) wel hij neemt daar al iets voor (.) dus wat dat

de dokter hier de slaapdokter voorstelt is dat hij een medicament neemt (.)maar eigenlijk

neemt hij dat al (.) dat is Nestolan

I will also check his medication. Well he's already taking something for it (.) so what

the doctor here (.) the sleep doctor (.) suggests is that he takes medication (.) but

actually he's been taking it already (.) that is Nestolan.

\footnotetext{
79 I الت للك داك الدوا اللي كتب للك الطبيب ديال النعاس، كا تاخدوه؟ الدوا تاع نستولان، كتاخده في اللبيل

she says the medication that the doctor prescribed for you the ones for the sleeping disorder, are you still taking them? Do you take Nestolan during the night?
}

80 D: $\quad / /$ dat had hij allemaal niet mee vorige keer (.) dat is goed dat hij het nu mee heeft // that he didn't have with him last time (.)ilt is good that he has them with him

now

$81 \mathrm{P:} \quad / /$ Lا

//aha

82 I: neen niet bij no not with him 
Box 4. (D: doctor; I: interpreter; P: patient; ४: direction of gaze; //: overlapping talk).
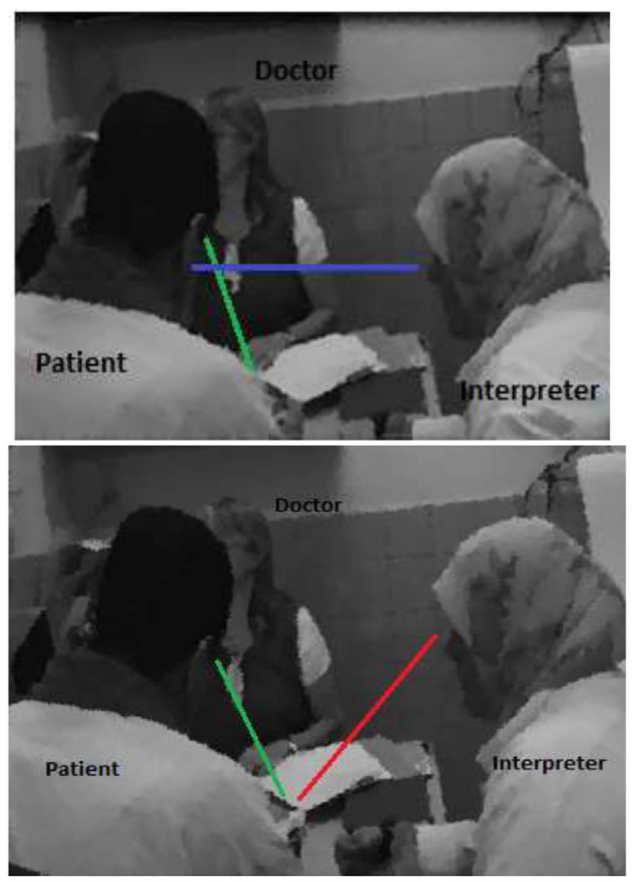

$78 \mathrm{D} 4$ computer screen: I will also check his

medication. Well he's already taking ones

something for it. So, what the doctor here, the sleep doctor, suggests is that he takes medication.

But actually he's been taking it already. That is

Nestolan.

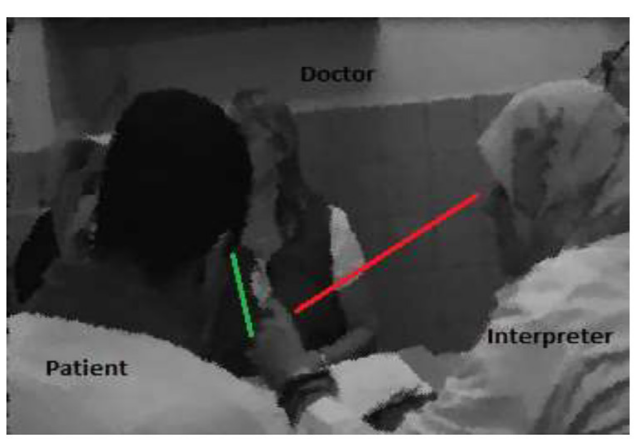

80 D 4 computer screen: // that he didn't have with him last time. It is good that he has them with him now.

81 P 4patient's pills: //aha

82 I 4 patient's pills: no, not with him
79 I patient's pills: she says the medication that the doctor prescribed for you, the for sleeping are you still taking them? Do you take Nestolan during the night? 
Box 5. (D: doctor, P: patient, I: interpreter; (.): pause shorter than 2secs; //: overlapping talk).

105 P: Да это письмо говорит о том (.) что теперь я не буду платить за ( ) (.) Но как это можно в одной больнице в двух местах не платить а здесь я должна платить что ли? // Я не понимаю

yes here I have a letter which says (.) the letter is about the fact that I don't need to pay (.) how is it possible that I don't pay in one hospital in two different places and that I have to pay here? //I don't understand

106 D:

$$
\text { // als ik }
$$

natuurlijk (.) ik zal e:: de consultatie hier moeten afronden (.) ja zeg maar hé (.)

$$
\text { // of course if I }
$$

(.)l will eh:: have to wind up here (.) yes tell me (.)

107 I:

mevrouw zegt//

the lady says//

$108 \mathrm{D}:$

//ja

//yes

109 I: een brief van de mutualiteit en in de brief is aangeduid dat ik consultaties e: in verband e:

in

verband met de huisarts//

a letter from the health insurance and in the letter it is pointed out that the consultations e: related e: to the GP//

$110 \mathrm{D}:$

$/ / \mathrm{ja}$

//yes

111 I: consultaties bij de nierspecialist//

consultations with the kidney consultant//

112 D:

//dat dat in orde zijn

//that they are ok 
Box 6. (D: doctor; I: interpreter; P: patient; 4: direction of gaze; //: overlapping talk; (.):pause shorter than 2secs).

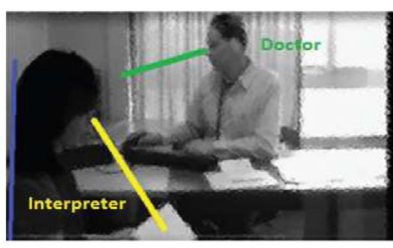

105 P yes here I have a letter

which says (.) the letter is about the fact that I

don't need to pay (.) how is it possible that I don't

pay in one hospital in two different places and that

I have to pay here? // I don't understand

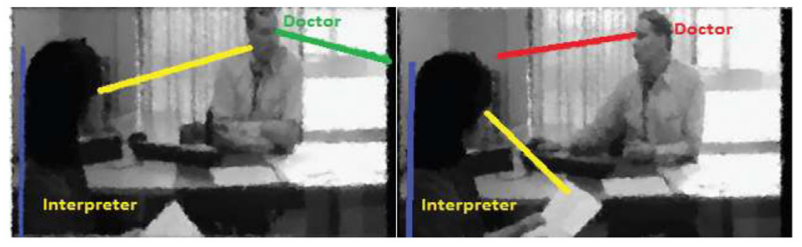

$106 \mathrm{~b}($.

$106 c$ D \computer screen I will eh:: have to

wind up here (.) yes tell me (.)


107 I 4 notes the lady says//

$108 \mathrm{D} 4$ computer //yes
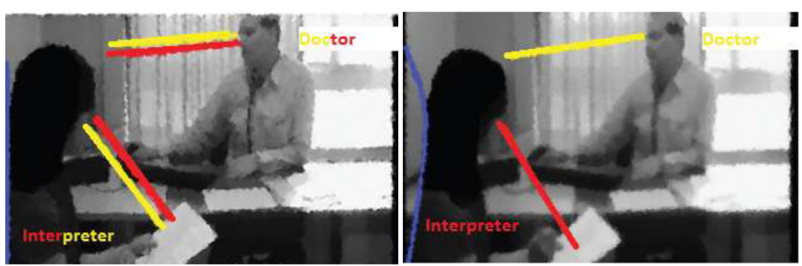

$109 \mathrm{I} 4$ notes a letter from the health insurance

and in the letter it is pointed out that the

111 I 4notes consultations with

the kidney consultant//

consultations e: related e: to the GP//

$110 \mathrm{D} \triangleleft$ computer screen $\quad / /$ yes

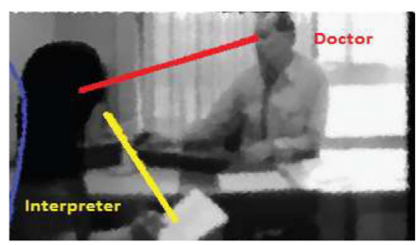

112 D 4 computer sereen //that they are ok

\section{Discussion and conclusion}

\subsection{Discussion}

We investigated how the patient's participation in interaction occurs in IMCs when the doctor provides information to the patient or tries to elicit information from them, and how the interpreter's presence in the consultation influences the patient's participation.

A recurrent pattern is that interpreters perform actions, both verbal and nonverbal, that go beyond the act of translating when rendering the doctor's utterances on provision of information or requests for information disclosure by the patient (research question 1). The interpreter's actions have an influence on the patient's participation in interaction either by enabling it or even clarifying it (research question 2).

We studied only the doctor's verbal utterances and their translation by the interpreter, focusing on the interpreter's actions during the rendition to the patient. We identified three main patterns in the interpreter's actions. The interpreters performed actions by employing different modes of nonverbal communication, such as complementing the verbal interaction with gaze, body orientation and gesture.

In all three categories, the interpreter's actions were characterized by increased visibility in terms of both verbal and nonverbal interaction. This provides further evidence of the interpreter being a fully-fledged participant in interaction in a way similar to that of the doctor and the patient. Increased visibility emerged from the interpreter's assumption of the roles of author and principal that come with increased responsibility which the interpreter holds for the meaning expressed in interaction (e.g. when the interpreter introduced a new question on her own initiative, Box 4). When the interpreter verbally performed as author/principal, their nonverbal behaviour complemented and reinforced their verbal communication toward the doctor and the patient. It could be argued that this stance might facilitate the patient's participation (e.g. by ensuring the patient is granted the opportunity to speak). Alternatively, it could result in the patient's participation being compromised in the long run. This could be the case if, for instance, an interpreter-patient PEF prompted the patient to engage in verbal and nonverbal interaction only with the interpreter and prevented the patient from interacting nonverbally with the doctor. In that case, the interpreter's action would place the patient more in the background of the doctor-patient interaction, although seemingly such an action would aim to safeguard the patient's participation. This could pose barriers in the doctor's attempts to employ a patient-centred style of communication.

Reflecting on the interpreter's actions in interaction with the doctor and the patient and revisiting them through the lens of Task, it could be argued that both the interpreter and the doctor are in certain respects not always following the normative frameworks that apply to their respective professions. By addressing the interpreter instead of the patient (verbally and nonverbally), doctors do not encourage the patient's participation. In patientcentred medicine, it is the doctor's responsibility to help patients participate in the consultation [21]. Interpreters on the other hand, by not taking action to ensure the neutral position they should be expected to maintain and by taking the initiative to involve the patient in the interaction as much as possible, they, too, seem to somehow disregard the principle of neutrality and impartiality that is stipulated in the code of their professional conduct. This often occurs because interpreters are normally expected to give as close an equivalent as possible and strive for impartiality and transparency at all times.

In cases where the doctor's actions do not immediately relate to the patient but to the interpreter, the interpreter might act in a proactive manner and on behalf of the patient. As is evident from 
Boxes 4 and 6, even an indirect address of the interpreter by the doctor (e.g. the doctor referring to the patient in 3rd person) might prompt the interpreter to step out of the normative role and act as a participant assuming increased responsibility. It can be argued that an efficient side-interaction between the doctor and the interpreter could only facilitate the doctor-patient communication and therefore would be likely to safeguard the patient's participation in the consultation. However, this would incur a change in the interactional dynamics and could deprive the patient from the focal position. Alternatively, the interpreter might opt to adhere to the principle of completeness in translation, to the extent that they might exert power over the doctor (Box 6), asking them to comply with the rules on interpreter-mediated interaction that interpreters are requested to announce to the doctor and the patient at the start of the consultation.

The above analysis has provided evidence of actions performed by doctors and interpreters which seem to be in contrast to aspects of the normative frameworks that apply to both professions. This is, however, based only on the observation of the doctors' and interpreters' behaviour in interaction and does not by any means apply to both groups of professionals across the board. Strikingly, both the doctor and the interpreter, as was shown above, work towards reaching mutual understanding with the patient, something which hopefully leads to the latter's participation in the consultation. However, in our study, we found that despite the common objective which the doctor and the interpreter ultimately pursue, they seem to work towards it by departing from a rather mono-professional stance without taking into account the other profession's normative framework. Teaching both doctors and interpreters to depart from an interprofessional stance could allow for synchronized and collaborative practice at the level of interaction between doctors and interpreters. This, by extension, would encourage both professionals to perform actions that collectively enhance the patient's participation in the consultation.

The findings of the study suggest that interpreters communicate more with patients by engaging with them both verbally and nonverbally than they do with doctors. However, the interpreters in our study did so when they were translating the doctor's utterance for the patient, thus addressing the latter. Speakers' use nonverbal means, such as gaze, toward a participant is an explicit form of addressing that participant [22].

The limited size of the dataset in our study does not allow us to generalize our findings. The analytical tool used for this study allows only for the observation of participants' behaviour and does not capture participants' intentions or cultural influences. Coded utterances were discussed among authors until consensus was reached. Follow-up studies should consider calculating inter-coder reliability. Future work could test the relevance of our findings in a larger and more diverse dataset.

\section{Conclusion}

Both doctors and interpreters should become more aware of their own and each other's actions in interaction and their impact on the patient's participation in the consultation.

\section{Practice implications}

Awareness of the doctors' own and interpreters' actions should start as early as at undergraduate level and could be achieved by means of interprofessional education.

\section{Funding}

This research did not receive any specific grant from funding agencies in the public, commercial, or not-for-profit sectors.

\section{Acknowledgements}

The data were collected by the first author during her appointment at Ghent University. The first author has sought and obtained Ghent University's permission to report on the data.

\section{References}

[1] L.C. Marla, L.B. Carma, C. Betty, M. Gregory, The impact of patient participation in health decisions within medical encounters: a systematic review, Med. Decis. Mak. 36 (4) (2015) 427-452.

[2] J.D. Robinson, D.R. Hoover, M.K. Venetis, T.J. Kearney, R.L. Street Jr., Consultations between patients with breast cancer and surgeons: a pathway from patient-centered communication to reduced hopelessness, J. Clin. Oncol. 31 (3) (2013) 351-358.

[3] T.A. D'Agostino, T.M. Atkinson, L.E. Latella, M. Rogers, D. Morrissey, A.P. DeRosa, P.A. Parker, Promoting patient participation in healthcare interactions through communication skills training: a systematic review, Patient Educ. Couns. 100 (7) (2017) 1247-1257.

[4] P. Andreassen, M.A. Neergaard, T. Brogaard, M.H. Skorstengaard, A.B. Jensen, Talking about sensitive topics during the advance care planning discussion: a peek into the black box, Palliat. Support. Care 13 (6) (2015) 1669-1676.

[5] H. Ishikawa, H. Hashimoto, D.L. Roter, Y. Yamazaki, T. Takayama, E. Yano, Patient contribution to the medical dialogue and perceived patientcenteredness, J. Gen. Intern. Med. 20 (10) (2005) 906-910.

[6] C.R. Sanderson, P.J. Cahill, J.L. Phillips, A. Johnson, E.A. Lobb, Patient-centered family meetings in palliative care: a quality improvement project to explore a new model of family meetings with patients and families at the end of life, Ann. Palliat. Med. (2017) S195-S205.

[7] K. Ekberg, C. Meyer, N. Scarinci, C. Grenness, L. Hickson, Family member involvement in audiology appointments with older people with hearing impairment, Int. J. Audiol. 54 (2) (2015) 70-76.

[8] D.E. Brashers, D.J. Goldsmith, E. Hsieh, Information seeking and avoiding in health contexts, Hum. Commun. Res. 28 (2) (2002) 258-271.

[9] L. Kaczmarek, Towards a broader approach to the community interpreter's role on correspondence between role perceptions and interactional goals, Interpreting 18 (1) (2016) 57-88.

[10] D. Krystallidou, The Interpreter's Role in Medical Consultations as Perceived and as Interactionally Negotiated: a Study of a Flemish Hospital Setting, Using Interview Data and Video Recorded Interactions, PhD Thesis, Ghent University, 2013.

[11] M. Sleptsova, G. Hofer, N. Morina, W. Langewitz, The role of the health care interpreter in a clinical setting-a narrative review, J. Commun. Health Nurs. 31 (3) (2014) 167-184.

[12] E. Davitti, Dialogue interpreting as intercultural mediation interpreters' use of upgrading moves in parent-teacher meetings, Interpreting 15 (2) (2013) 168199.

[13] D. Krystallidou, Investigating the interpreter's role(s): the a.R.T. framework, Interpreting 18 (2) (2016) 172-197.

[14] G. Flores, M.B. Laws, S.J. Mayo, B. Zuckerman, M. Abreu, L. Medina, E.J. Hardt, Errors in medical interpretation and their potential clinical consequences in pediatric encounters, Pediatrics 111 (1) (2003) 6-14.

[15] G. Flores, M. Abreu, C.P. Barone, R. Bachur, H. Lin, Errors of medical interpretation and their potential clinical consequences: a comparison of professional versus ad hoc versus no interpreters, Ann. Emerg. Med. 60 (5) (2012) 545-553.

[16] J.B. Bavelas, N. Chovil, L. Coates, L. Roe, Gestures specialized for dialogue, Pers. Soc. Psychol. Bull. 21 (4) (1995) 394-405.

[17] S.C. Levinson, Putting linguistics on a proper footing: explorations in Goffman's concepts of participation, in: P. Drew (Ed.), Exploring the Interaction Order, University of Pennsylvania Press, 1988.

[18] C. Goodwin, Conversational Organization: Interaction between Speakers and Hearers, Academic Press, New York, 1981.

[19] D. Krystallidou, Gaze and body orientation as an apparatus for patient inclusion into/exclusion from a patient-centred framework of communication, Interpret. Transl. Train. 8 (3) (2014) 399-417.

[20] M. Argyle, M. Cook, Gaze and Mutual Gaze, Cambridge University Press, Cambridge, 1976.

[21] R.M. Epstein, R.L. Street, The values and value of patient-centered care, Ann. Fam. Med. 9 (2) (2011) 100-103.

[22] G.H. Lerner, Selecting next speaker: the context-sensitive operation of a context-free organization, Lang. Soc. 32 (2) (2003) 177-201. 